\title{
Electrogeneration of Superoxide Ion at Polyaniline-modified Electrodes in Aqueous Media
}

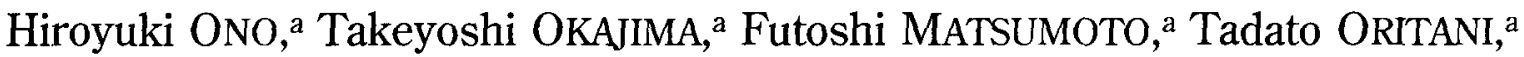 \\ Akihito SHIMIZU, ${ }^{\mathrm{b}}$ Mitsuo TAKAHASHI, ${ }^{\mathrm{b}}$ and Takeo OHSAKA, ${ }^{\mathrm{a}}{ }^{\mathrm{a}}$
}

\begin{abstract}
${ }^{a}$ Department of Electronic Chemistry, Interdisciplinary Graduate School of Science and Engineering, Tokyo Institute of Technology (4259 Nagatsuta, Midori-ku, Yokohama 226-8502, Japan)

bDepartment of Chemical Science and Engineering, Tokyo National College of Technology (1220-2 Kunugida, Hachiouji, Tokyo 193-0997, Japan)
\end{abstract}

Received June 18, 2001 ; Accepted July 18, 2001

\begin{abstract}
Electrogeneration of superoxide ion $\left(\mathrm{O}_{2}{ }^{-}\right)$with polyaniline (PAn)-modified indium-tin oxide (ITO) electrodes has been examined in alkaline aqueous media. The PAn-modified electrode showed electrocatalytic activity for $\mathrm{O}_{2}$ reduction. Specific reactions of cytochrome $c$ (cyt. $c\left(\mathrm{Fe}^{3+}\right)$ ), nitroblue tetrazolium salt analogue (WST-4) and superoxide dismutase (SOD) with $\mathrm{O}_{2}{ }^{-}$have been successfully applied to confirm the electrogeneration of $\mathrm{O}_{2}{ }^{-}$. The results demonstrate that the PAn-modified electrode is useful for the electrogeneration of $\mathrm{O}_{2}{ }^{-}$via a redox-mediated reduction of $\mathrm{O}_{2}$ in alkaline aqueous media.
\end{abstract}

Key Words : $\mathrm{O}_{2}$ Reduction, Superoxide Ion, Polyaniline, Superoxide Dismutase

\section{Introduction}

Recently, it has been recognized that superoxide ion $\left(\mathrm{O}_{2}{ }^{-}\right)$may convert to most of other reactive oxygen species as a primary precursor, and that many of biological phenomena such as aging, inflammation and various diseases may be attributed to direct or indirect action of $\mathrm{O}_{2}{ }^{-}$on biological tissues. ${ }^{1)}$ The electrogeneration of $\mathrm{O}_{2}{ }^{-}$ at electrodes is a useful tool in the elucidation of the reaction of $\mathrm{O}_{2}^{-}$in a living body and, especially, kinetic analysis of fast biochemical reactions between $\mathrm{O}_{2}{ }^{-}$and physiologically important substances, because an arbitrary amount of $\mathrm{O}_{2}^{-}$can be supplied quickly to the system examined. Our group has demonstrated that $\mathrm{O}_{2}{ }^{-}$is generated by one-electron reduction of molecular oxygen $\left(\mathrm{O}_{2}\right)$ on the electrode covered with hydrophobic layer using quinolines ${ }^{2)}$ and thiophenol ${ }^{3)}$ in aqueous alkaline solutions. Recently, Morita ${ }^{4)}$ reported that adding chemically synthesized polyaniline (PAn) powder into $\mathrm{O}_{z}$ saturated water produced $\mathrm{H}_{2} \mathrm{O}_{2}$ via a disproportionation of $\mathrm{O}_{2}{ }^{-}$generated by one-electron transfer reaction from the reduced PAn to $\mathrm{O}_{2}$. This report has encouraged us to study the $\mathrm{O}_{2}{ }^{-}$generation at PAn-modified electrodes in aqueous solutions. In this study, we examined the $\mathrm{O}_{2}{ }^{-}$ generation via a redox-mediated reduction of $\mathrm{O}_{2}$ at PAnmodified indium-tin oxide (ITO) electrodes in aqueous media.

\section{Experimental}

Aniline (Kanto Chemical Co.) was of reagent grade, and was used after purification. Cytochrome $c$ (cyt. $c$ $\left(\mathrm{Fe}^{3+}\right)$ ) from horse heart (cyt.c; type VI, purity $>99 \%$ ) and superoxide dismutase (SOD) from bovine erythrocyte (SOD; EC. 1. 15. 1. 1, copper-zinc type, 3800 units $\mathrm{mg}^{-1}$ ) were purchased from Sigma Chemical Company and Wako Pure Chemical Industries, respectively. WST$4,{ }^{5)}$ a novel analogue of nitroblue tetrazolium salt, was available from Dojin Chemical Company. All other chemicals were of reagent grade. PAn was prepared from 10 $\mathrm{mM}$ aniline solution containing $0.1 \mathrm{M}$ sodium dodecylbenzensulfonate (SDBS) by scanning repeatedly the electrode potential between -0.2 and $1.0 \mathrm{~V}$ vs. $\mathrm{Ag}|\mathrm{AgCl}|$ $\mathrm{KCl}$ (sat) at $50 \mathrm{mVs}^{-1}$ for 50 times. The reduced form of PAn was obtained by the reduction treatment of the electrochemically synthesized PAn with hydrazine monohydrate for a week. ${ }^{6}$ )

\section{Results and Discussion}

\section{3. $1 \mathrm{O}_{2}$ reduction at $\mathrm{PAn}$-modified ITO electrodes}

Figure 1 shows the typical cyclic voltammograms obtained at bare and PAn (film thickness: $10 \mathrm{~nm}$ )-modified ITO $\left(0.5 \mathrm{~cm}^{2}, 10 \Omega \mathrm{cm}^{-1}\right)$ electrodes in $\mathrm{O}_{2}$ or $\mathrm{N}_{2}$-saturated $0.1 \mathrm{M} \mathrm{Na}_{2} \mathrm{~B}_{4} \mathrm{O}_{7} / \mathrm{NaOH}$ buffer solutions ( $\mathrm{pH}$ 9.4). The redox response obtained at the PAn-modified electrode under $\mathrm{N}_{2}$ atmosphere is very broad, but it is apparently distinguishable from the blank response obtained at the bare electrode. Under $\mathrm{O}_{2}$ atmosphere much larger cathodic current was observed at the PAn-modified electrode than at the bare electrode and at the same time the anodic current corresponding to the reoxidation of PAn decreased remarkably, as can be seen from the comparison of Figs. 1-(b) and (c). Therefore, the $\mathrm{O}_{2}$ reduction at the PAn-modified ITO electrode was considered to proceed electrocatalytically. Such an electrocatalytic $\mathrm{O}_{2}$ reduction at the PAn-modified ITO electrode was not observed in acidic and neutral solutions. 


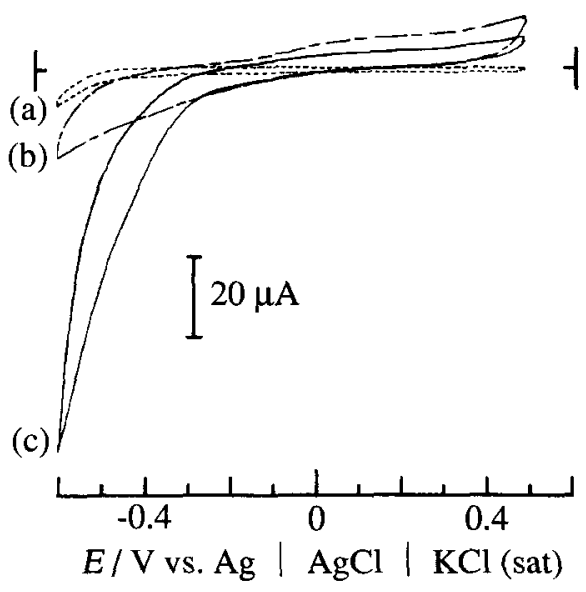

Fig. 1 Typical cyclic voltammograms recorded at (a) bare and (b, c) PAn-modified ITO electrodes in $0.1 \mathrm{M} \mathrm{Na}_{2} \mathrm{~B}_{4} \mathrm{O}_{7} /$ $\mathrm{NaOH}$ buffer solution (pH 9.4) under (a, c) $\mathrm{O}_{2}$ and (b) $\mathrm{N}_{2}$ atmosphere. The potential sweep rate is $50 \mathrm{mVs}^{-1}$.

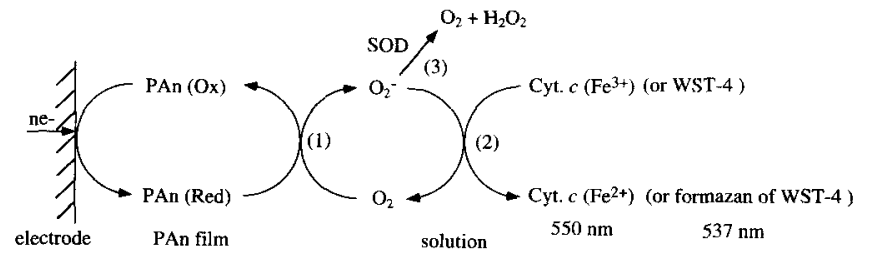

Scheme 1 Schematic depiction of electrogeneration of $\mathrm{O}_{2}{ }^{-}$at PAn-modified electrode and its detection reactions. PAn (Ox) and PAn (Red) represent the oxidized and reduced forms of PAn, respectively. Reactions (1), (2) and (3) represent the reduction of $\mathrm{O}_{2}$ by the PAn (Red), the reduction of cyt. $c$ $\left(\mathrm{Fe}^{3+}\right)$ (or WST-4) by $\mathrm{O}_{2}^{-}$and the spontaneous and SODcatalyzed disproportionation of $\mathrm{O}_{2}{ }^{-}$, respectively.

\section{2 Detection of electrogenerated $\mathrm{O}_{2}^{-}$by cyt. $\mathrm{c}$ and WST-4}

The $\mathrm{O}_{2}{ }^{-}$generation based on the $\mathrm{O}_{2}$ reduction at the PAn-modified ITO electrode was examined using ferric cyt. $c\left(\mathrm{Fe}^{3+}\right)$ and WST-4 (scheme 1). The reductions of cyt. $c\left(\mathrm{Fe}^{3+}\right)$ and WST-4 with $\mathrm{O}_{2}{ }^{-}$are well known to result in the specific absorption spectra of cyt. $c\left(\mathrm{Fe}^{2+}\right)$ and the reduced form (formazan) of WST-4 at $c a .550 \mathrm{~nm}^{7}$ and $c a .537 \mathrm{~nm},{ }^{5}$ respectively. The measurement of these absorption spectra has been frequently made to confirm the generation of $\mathrm{O}_{2}{ }^{-}$in vivo and in vitro systems.

Figure 2 shows the visible absorption spectra of cyt. $c$ $\left(\mathrm{Fe}^{3+}\right)$ solution which was electrolyzed at $-0.5 \mathrm{~V}$ for $1 \mathrm{~h}$ using the bare and PAn-modified ITO electrodes under $\mathrm{O}_{2}$ or $\mathrm{N}_{2}$ atmosphere. The strong absorption peak characteristic of cyt. $c\left(\mathrm{Fe}^{2+}\right)$ was clearly observed at $550 \mathrm{~nm}$ when the cyt. $c\left(\mathrm{Fe}^{3+}\right)$ solution was electrolyzed at the PAn-modified electrode under $\mathrm{O}_{2}$ atmosphere. In addition, in this case, the intensity of the absorption peak at 550 $\mathrm{nm}$ was found to largely depend on the presence and the absence of SOD enzyme, which efficiently catalyzes the disproportionation of $\mathrm{O}_{2}{ }^{-}$to $\mathrm{O}_{2}$ and $\mathrm{H}_{2} \mathrm{O}_{2},{ }^{8}$ in the electrolytic solution. That is, the intensity was, as expected, higher in the absence of SOD than in its presence (see

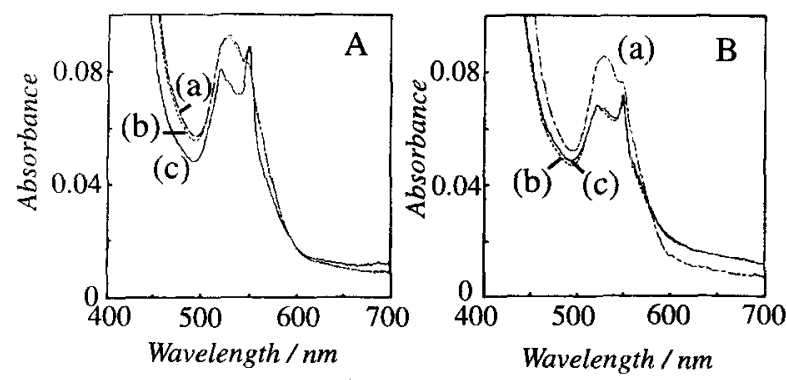

Fig. 2 Typical visible absorption spectra obtained before (a) and after $(b, c)$ the electrolysis of $0.1 \mathrm{M} \mathrm{Na}_{2} \mathrm{~B}_{4} \mathrm{O}_{7} / \mathrm{NaOH}$ buffer solution (pH 9.4) containing $8 \mu \mathrm{M}$ cyt. $c\left(\mathrm{Fe}^{3+}\right.$ ) and 5 mM EDTA with (A) PAn-modified and (B) bare ITO electrodes under (a, c) $\mathrm{O}_{2}$ and (b) $\mathrm{N}_{2}$ atmosphere. The electrode potential in each electrolysis was kept at $-0.5 \mathrm{~V}$ vs. $\mathrm{Ag}$ $|\mathrm{AgCl}| \mathrm{KCl}$ (sat) for $1 \mathrm{hr}$.

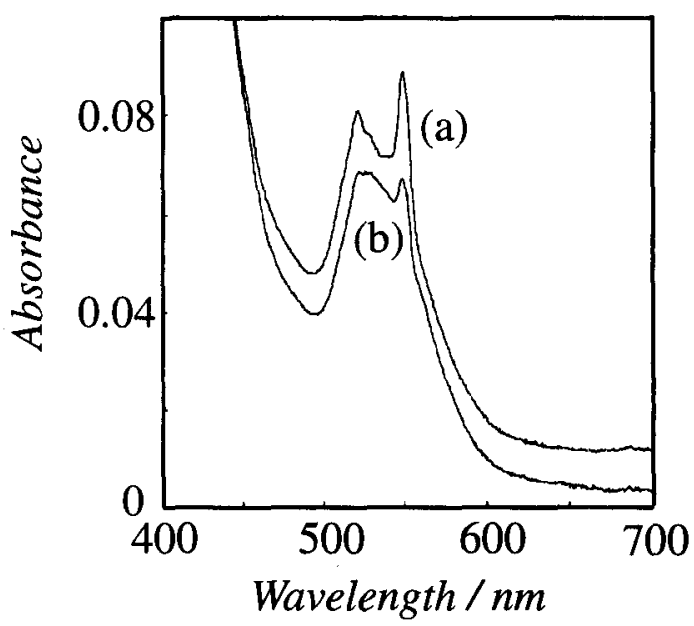

Fig. 3 Typical visible absorption spectra recorded after the electrolysis of $\mathrm{O}_{2}$-saturated $0.1 \mathrm{M} \mathrm{Na}_{2} \mathrm{~B}_{4} \mathrm{O}_{7} / \mathrm{NaOH}$ buffer solution ( $\mathrm{pH} 9.4$ ) containing $8 \mu \mathrm{M}$ cyt. $c\left(\mathrm{Fe}^{3+}\right)$ and $5 \mathrm{mM}$ EDTA with PAn-modified ITO electrode in the absence (a) and presence (b) of $0.5 \mu \mathrm{M}$ SOD. The electrode potential in each electrolysis was kept at $-0.5 \mathrm{~V}$ vs. $\mathrm{Ag}|\mathrm{AgCl}| \mathrm{KCl}$ (sat) for $1 \mathrm{hr}$.

Fig. 3). The absorption at $550 \mathrm{~nm}$ was also observed, even though weak, when the electrolysis was carried out at the PAn-modified electrode under $\mathrm{N}_{2}$ atmosphere (Fig. $2 \mathrm{~A}-\mathrm{b}$ ) and at the bare electrode under $\mathrm{N}_{2}$ and $\mathrm{O}_{2}$ atmosphere (Figs. 2B-b and c). This may be due to the direct reduction of cyt. $c\left(\mathrm{Fe}^{3+}\right)$ on the electrode surface. These results conclude that $\mathrm{O}_{2}{ }^{-}$can be generated via an electroreduction of $\mathrm{O}_{2}$ at the PAn-modified ITO electrode in weak alkaline aqueous solution. In other words, the reduced form of PAn can function as an effective oneelectron reducing agent for $\mathrm{O}_{2}$. The generated $\mathrm{O}_{2}{ }^{-}$ions spontaneously disproportionate into $\mathrm{O}_{2}$ and $\mathrm{H}_{2} \mathrm{O}_{2}$. Thus, the above-mentioned detection reaction of $\mathrm{O}_{2}{ }^{-}$using cyt. $c\left(\mathrm{Fe}^{3+}\right)$ competes with the spontaneous disproportionation of $\mathrm{O}_{2}^{-}$.

To further confirm the electrogeneration of $\mathrm{O}_{2}{ }^{-}$at the PAn-modified electrode, the following experiment was carried out. That is, we examined the reactions of $\mathrm{O}_{2}$ 

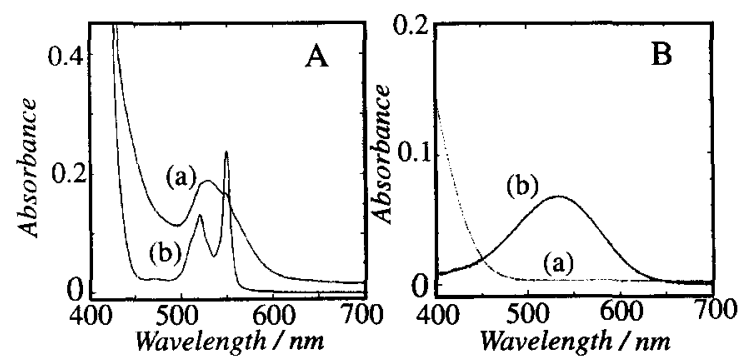

Fig. 4 Visible absorption spectra of (A) cyt. $c\left(\mathrm{Fe}^{3+}\right)$ and (B) WST- 4 solutions before (a) and after (b) $65 \mathrm{mg}$ of PAn powder (reduced form) was added into $\mathrm{O}_{2}$-saturated $0.1 \mathrm{M}$ $\mathrm{Na}_{2} \mathrm{~B}_{4} \mathrm{O}_{7} / \mathrm{NaOH}$ buffer solution ( $\mathrm{pH} 9.4$ ) containing $20 \mu \mathrm{M}$ cyt. $c\left(\mathrm{Fe}^{3+}\right)$ (or WST-4) and $5 \mathrm{mM} \mathrm{EDTA}$.

with the reduced form of the electrochemically synthesized PAn powder using cyt. $c\left(\mathrm{Fe}^{3+}\right)$ and WST-4 in the same aqueous solution as that used above. The results are shown in Fig. 4. When the reduced form of the PAn powder was added into $\mathrm{O}_{2}$-saturated solutions containing cyt. $c\left(\mathrm{Fe}^{3+}\right)$ and WST-4, the absorption peaks characteristic of cyt. $c\left(\mathrm{Fe}^{2+}\right)$ and the formazan of WST-4 could be clearly observed at $c a .550$ and $537 \mathrm{~nm}$, respectively. Of course, such characteristic absorption peaks could not be obtained when the reduced form of the PAn powder was added into $\mathrm{N}_{2}$-saturated solutions of cyt. $c\left(\mathrm{Fe}^{3+}\right)$ and WST-4. These results along with the ESR data reported by Otsuka et al. ${ }^{4}$ support the above-mentioned conclusion.

\section{Conclusions}

The $\mathrm{O}_{2}{ }^{-}$generation by the electroreduction of $\mathrm{O}_{2}$ with the PAn-modified ITO electrode in alkaline aqueous media was investigated. The PAn-modified electrode showed the electrocatalytic activity for $\mathrm{O}_{2}$ reduction. The efficient generation of $\mathrm{O}_{2}{ }^{-}$via a redox-mediated reduction of $\mathrm{O}_{2}$ at the PAn-modified electrode could be confirmed by use of indicator methods with cyt. $c\left(\mathrm{Fe}^{3+}\right)$, SOD and WST-4. The PAn-modified electrode can be used for the electrogeneration of $\mathrm{O}_{2}{ }^{-}$in alkaline aqueous media.

\section{Acknowledgements}

The present work was financially supported by Grantin-Aids for Scientific Research (No. 12875164) and Scientific Research (A) (No. 10305064), for T. Ohsaka, from the Ministry of Education, Science, Sports, Culture and Technology, Japan.

\section{References}

1) M. A. J. Rodgers and E. L. Poweres(Eds.), Oxygen and Oxyradicals in Chemistry and Biology, Academic Press, New York (1981).

2) F. Matsumoto, K. Tokuda, and T. Ohsaka, Electroanalysis, 8, 648 (1996).

3) F. Matsumoto, K. Tokuda, and T. Ohsaka, Denki Kagaku (presently Electrochemistry), 63, 1205 (1995).

4) S. Otsuka, K. Saito, and K. Morita, Chem. Lett., 1996, 615.

5) T. Oritani and T. Ohsaka, manuscript in preparation.

6) D. -K. Moon, M. Ezuka, T. Maruyama, K. Osakada, and T. Yamamoto, Macromolecules, 26, 364 (1993).

7) L. Packer and A. N. Glazer(Eds.), Methods in Enzymology, 186 (1990).

8) S. Marklund, J. Biol. Chem., 251, 7504 (1976). 